\title{
Advancing age: bane or boon?
}

\author{
Srinivasan Muralidharan ${ }^{1}$
}

Received: 27 November 2020 / Accepted: 8 December 2020 / Published online: 22 February 2021

(C) Indian Association of Cardiovascular-Thoracic Surgeons 2021

The editorial was rather timely and I felt it was specifically addressed to me. I had recently been put to pasture after 34 years in the same hospital. When I joined this unit, it was a very basic setup and needed an injection of fresh blood, ideas and lots of hard work. This pioneering work to establish a working excellent surgical facility, with a focus on education and training, was launched. We started a teaching programme leading to a Diplomate National Boards (DNB) and had successive batches of budding cardiac surgeons opting for the programme with us, along with a robust surgical facility.

Our trainees qualified and most of them went abroad to enhance their skills and returned. Our situation was unique, as our first trainee joined us and grew to take over as the "chair" a few years ago.

The teacher who is indeed wise does not bid you enter the house of his wisdom, but leads you to that threshold of your mind. Khalil Gibran

I was often asked what were my retirement plans, alas I had none. I suffered from tubular vision-work, work and work. Over the years, I began to delegate work to my colleagues. The training programme continued, the unit was on firm ground and my presence was not absolutely necessary. I learned when not to do things and when to call for help when needed. I managed to impart that concept of knowing one's limitations to the younger generation.

The man with insight enough to admit his limitations comes nearest to perfection. Johann Wolfgang von Goethe

Coming to retirement-should you go on your own or be asked to leave? Neither had my surgical skill diminished, nor

Srinivasan Muralidharan

drmurali42@gmail.com

1 Department of Cardiothoracic Surgery, G.Kuppuswamy Naidu Memorial Hospital, Coimbatore, India my vision. The hands were still steady. The experience was indeed an overwhelming positive. One fine day I was informed that the "Board" had decided that none above 75 years of age should be operating. No credentialing committee, no peer review. This was an arbitrary decision by a non-medical board. "Age is just a number".

Is this the right way to go? In the private/corporate sector, there is no pension or gratuity. One has to plan for the future during his productive years. As cardiac surgeons, we are supposed to be calm under pressure in high-stakes situations, get used to hard work and possess great stamina and resilience.

A surgeon's workload is very much expected to be vigorous. Dr. Hubka

Finally, having been thrown into the deep end of the pool, you have to swim and continue your life. Networking and friends matter. It helps if you have a supportive family, which gets to see you a lot more than they ever did before. It is an allnew experience for them as well. Reflect on these thoughts.

Funding None.

\section{Compliance with ethical standards}

Conflict of interest The author declares that he has no conflict of interest.

Ethics approval Not applicable.

Consent to participate Not applicable.

Consent for publication Not applicable.

Publisher's note Springer Nature remains neutral with regard to jurisdictional claims in published maps and institutional affiliations. 